\title{
The behavior of $\mathrm{Li}$ and $\mathrm{Mg}$ isotopes during organic-mediated silicate weathering
}

\author{
XIANYI LIU ${ }^{1}$, PHILIP A E POGGE VON STRANDMANN ${ }^{2,3}$, \\ ERIC H. OELKERS ${ }^{4}$ AND WESLEY FRASER ${ }^{5}$ \\ ${ }^{1} \mathrm{UCL}$ \\ ${ }^{2}$ JGU Mainz \\ ${ }^{3}$ University of Mainz \\ ${ }^{4}$ Geosciences Environnement Toulouse \\ ${ }^{5}$ Oxford Brookes University \\ Presenting Author: xianyi.liu.19@ucl.ac.uk
}

The emergence and continental retainment of soils and copious clay minerals is believed to be coupled to the rise of land plants. Organic compounds (such as acids) secreted by plants roots may play an important role in triggering or altering clay mineral formation during silicate weathering. Herein, to test the relationship between common plant organic compounds and clays, organic-water rock interaction experiments have been conducted. Five common organic compounds with concentrations of $0.01 \mathrm{M}$ have been added to the batch reactors containing lake sediments and water with a rock/water ratio of $1: 10$. These experiments are compared to the abiotic control groups with $0.01 \mathrm{M} \mathrm{HCl}$ and water, respectively. The experiments last for 9 months and are regularly sampled. Fluid elemental concentrations are measured to track the mineral dissolution and precipitation processes. The evolution of aqueous lithium (Li) isotopes which can trace the amount of secondary minerals precipitated is obtained to quantify the roles of different organics played in clay formation. Rayleigh and Batch fractionation models are applied to evaluate the features of lithium isotopic evolution. PHREEQC modelling that calculates the saturation states of secondary minerals are conducted to assist the $\mathrm{Li}$ isotope interpretations. In all cases, solution $\delta^{7} \mathrm{Li}$ rapidly increases, but the fractionation and amount of $\mathrm{Li}$ taken up by secondary minerals varies according to organic acid type. Aqueous $\mathrm{Mg}$ isotopes are also obtained and compared to $\mathrm{Li}$ isotopes in terms of the response to the clay minerals formation. These experiments can deepen our understanding of plantmediated silicate weathering. 